\title{
The choice between epidermal and neural fate: a matter of calcium
}

\author{
MARC MOREAU* and CATHERINE LECLERC \\ Developmental Biology Centre, Paul Sabatier University, Toulouse, France
}

\begin{abstract}
The development of the vertebrate embryo, which includes the induction and the patterning of the three germ layers, requires signaling among cells. In vertebrates, cells of the embryonic ectoderm have a choice during gastrulation between two fates; they give rise to epidermal progenitors on the ventral side and neural progenitors on the dorsal side. It was first shown by Spemann and Mangold in 1924 that the dorsal mesoderm (also called the SpemannMangold Organizer) has a potent biological capacity to induce nervous system from the adjacent ectoderm. A similar observation was reported in amniotes, indicating that neural induction by the Organizer is a conserved process controlling the initial steps in vertebrates neurogenesis. Molecular studies of the last decade have led to the identification of signaling molecules which participate in these embryonic decisions. Epidermis induction occurs through a signaling cascade involving Bone Morphogenetic Proteins (BMP 2, 4, 7) and receptor-regulated Smad proteins which translocate into the nucleus to form active transcriptional complexes. These molecules mediate BMPs effect to activate epidermal-specific gene expression and to repress neural-specific gene transcription. Neural fate is revealed by factors secreted by the dorsal mesoderm (Noggin, Chordin, Follistatin, ...) which act by blocking BMP signaling. Consequently, epidermal fate is an induced fate while neural fate is interpreted as a default state of the ectoderm. In this review, we describe the signaling pathways which act to determine the fate of the ectoderm and discuss an alternative model in which neural fate is not a default state. This new model integrates the activation of a calcium-dependent signaling pathway due to an influx of calcium through L-type calcium channels. In this model, calcium plays a central regulatory role. While calcium is required for neural determination, epidermal determination occurs when calcium-dependent signaling pathways are inactive.
\end{abstract}

KEY WORDS: neural induction, epidermal determination, transcription factor, amphibian

\section{Introduction}

Neural and epidermal tissues have the same embryonic origin, the ectoderm. In this territory, very early, in the embryo, a sort of binary process determines the cell fate, i.e.; if the cells are not committed in the epidermal fate, they are determined in the neural pathway. For these reasons, we cannot study the epidermal fate of cells without analyzing the neural determination. Major discoveries concerning the choice of neural or epidermal fates were made in amphibians and more particularly in Xenopus laevis.

In vertebrates, during gastrulation, the cells of the embryonic ectoderm give rise to epidermal progenitors in the ventral side and neural progenitors in the dorsal side. However, in Xenopus dorsal or ventral ectoderm isolated during blastula stage normally develops into epidermis when cultured in vitro. Since the experiments performed on the newt by Spemann and Mangold,
(1924), we know that the dorsal mesoderm (also called Spemann Organizer) grafted into the ventral side of a recipient gastrula, triggers the formation of a secondary axis with a normal anteroposterior and dorso-ventral axis in the host embryo. The ectopic dorsal mesoderm derived from donor, while the secondary nervous system was recruited from the host ectoderm, which was committed to produce epidermis. These results showed that, during gastrulation, embryonic ectoderm could be induced to form neural tissue in presence of a source of inducing signals secreted by the dorsal mesoderm, this process is called neural induction (Gilbert and Saxen, 1993). At this stage ectodermal cells choose between two fates, neural or epidermal. The role of neural induction is to trigger the respecification of ectoderm to become

Abbreviations used in this paper: BMP, bone morphogenetic protein; FGF, fibroblast growth factor; GFAP, glial fibrillary acidic protein; NCAM, neural cell adhesion molecule.

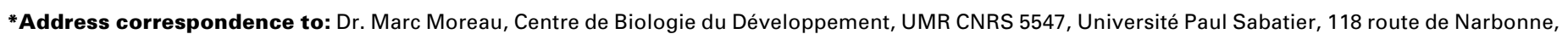
F-31062 Toulouse, France. e-mail: moreau@cict.fr 
neurectoderm leading to the formation of the nervous system of the adult, together with the imposition of anterior-posterior pattern (reviewed by Hamburger, 1988).

There is a conservation of neural induction mechanism in vertebrates. In fact experiments with chick or mouse embryos have shown the existence of organizing regions that could induce a secondary nervous system when transplanted into ectopic regions (Beddington, 1994; Waddington, 1933).

\section{The neural inducers}

Several neural inducers have been discovered in Xenopus, which respond to precise criteria: i) they have to be expressed at the right place (in dorsal mesoderm) and the right moment (at gastrula stages when neural induction occurs). ii) they should be secreted from the dorsal mesoderm and be able to act on the isolated ectoderm (animal cap) in a non-cell autonomous manner iii) the effect is direct, they should induce neural structures without inducing mesoderm.

Noggin was the first protein to be reported with a direct neural inducing activity (Lamb et al., 1993). Follistatin, an activin antagonist, (Hemmati-Brivanlou et al., 1994) and Chordin, (Sasai et al., 1994) have been also shown to have a direct neuralizing activity. These three factors injected as RNA or in vitro in animal cap assay, added in the external medium as a protein, induce the expression of neural-specific genes, such as the neural cell adhesion molecule gene (NCAM). No mesodermal markers are induced. Homologues of these neural inducers have been found in other vertebrates, including zebrafish, chick, mouse and human.

Xnr3, a Xenopus homologue of the mouse nodal gene (Hansen et al., 1997; Smith et al., 1995) and Cerberus, are also able to induce neural tissue (Bouwmeester et al., 1996). However, for Cerberus, the induction is accompanied by mesoderm formation and its effect may be indirect.

The fibroblast growth factor (FGF) receptor has also been proposed to mediate neural induction. A dominant negative FGF receptor, when introduced into isolated ectoderms blocks neural induction triggered by Noggin mRNA (Launay et al., 1996). However the same dominant negative FGF receptor, does not prevent neural induction in whole Xenopus embryos (Kroll and Amaya, 1996). Basic FGF (bFGF or FGF-2) has been reported to have direct neural-inducing activity when animal caps are incubated in low calcium and magnesium medium (Kengaku and Okamoto, 1995; Lamb and Harland, 1995) but bFGF does not induce neural fate in animal caps when added directly in the medium (Cox and Hemmati-Brivanlou, 1995).

\section{Dissociation inhibits epidermal fate and neuralizes the ectodermal cells}

When amphibian animal caps are dissociated in saline divalent ions free medium the cells changed their fates from epidermal to neural. They expressed neural specific markers (e.g., NCAM) and differentiated in neural and glial cells (Godsave and Slack, 1989; Grunz and Tacke, 1989; Saint-Jeannet et al., 1990; Sato and Sargent, 1989). The dissociated ectoderm was not exposed to the inducing effect of the dorsal mesoderm or to any other factors during the process. In amphibians in dissociation context, neural determination can occur autonomously without any inducers. Hemmati-Brivanlou and Melton (1992) obtained similar results when they injected into animal caps a truncated form of the type II activin. Under this treatment, the signaling by activin and BMP was inhibited and the injected animal caps adopted a neural instead of an epidermal fate. The authors proposed a model where epidermal fate is induced and depends of TGF- $\beta$ signaling while neural fate occurs by disruption of the epidermal-inducing pathway (Fig. 1). According to this model, the neural fate is the default fate of the ectodermal cells (Hemmati-Brivanlou and Melton, 1994).

\section{Bone Morphogenetic Proteins and epidermal induction}

The default model of neural induction predicts the existence of inhibitory signals in animal caps to block neural formation. Bone morphogenetic proteins (BMP), members of the TGF- $\beta$ family have been found to play this role. BMP family members interact through extracellular domains of heteromeric complexes composed of type I and type II of serine threonine kinase receptors. In general type II receptors are constitutive kinases responsible for ligand binding and for transphosphorylation of the type I receptor on a glycine-serine rich domain (GS domain). The phosphorylation of this domain activates the type I kinase which then phosphorylates downstream components of the signaling pathway (members of Smad family). Type I receptors are called activin-receptorlike-kinases (ALKs). ALK2, ALK3, ALK6 are implied in BMP transduction (for review see ltoh et al., 2000). For type II, it can be find BMP receptors type II and receptors for high affinity for activins (ActRII and ActR IIB).

Experiments performed by Wilson and Hemmati-Brivanlou, (1995) revealed that BMP4 was able to suppress expression of neural markers and induce epidermal keratin expression in dissociated ectodermal cells. BMP2 and BMP7, close relatives of BMP4, are also reported to be neural inhibitors and epidermal inducers in the context of dissociated cells (Suzuki et al., 1997b). In ectodermal cells, truncated type I BMP receptors (ALK2 and ALK3) (Sasai etal., 1995; Suzuki etal., 1997b; Suzuki etal., 1995; Xu et al., 1995), dominant negative BMP4 and BMP7 ligands (Hawley et al., 1995), antisense BMP4 RNA (Sasai et al., 1995) produce the same effect i.e. blocked epidermal determination and lead to neuralization. These data suggest that endogenous BMPs are, at least partly, responsible for maintaining epidermal specification in intact animal caps.

To explain the neuralization observed by dissociation of ectoderm cells it has been suggested a dilution of the BMPs. In fact, when BMP4 is added at high concentration during dissociation, the expression of neural markers is totally abolished (Wilson etal., 1997). However, some other explanations can be proposed, as we will see later in this article.

The discovery of BMPs as neural inhibitors and epidermal inducers suggested that neural inducers might work in vivo to block BMP signaling. In fact biochemical studies demonstrate that Noggin and Chordin bind directly with BMPs, this binding being specific (Piccolo et al., 1996; Zimmerman etal., 1996). By binding to BMPs, both Noggin and Chordin prevent BMPs from contacting their receptors, thus inhibiting signal transduction along the BMP pathway. Follistatin has previously been shown to interfere with a number of BMPs by the formation of inactive trimeric complex 
(Fainsod etal., 1997; lemura etal., 1999). Cerberus and Xnr3 may work in a similar way. Cerberus-dependent neural induction is inhibited by BMP4 (Bouwmeester et al., 1996). It is unclear at what level Cerberus and BMP4 interact, but it remains possible that Cerberus binds directly to BMP4. Moreover, BMP4 or an activated BMP receptor (Hansen et al., 1997) also blocks xnr3induced neural formation. A new ligand of the TGF- $\beta$ family, Growth and Differentiation Factor-6 (GDF6), is an other antagonist of neural inducers. In dissociated cells, GDF6 induces epidermis and inhibits neural tissues. Its activity is blocked by Noggin and it has been demonstrated that GDF6 binds directly to Noggin. GDF6 can form heterodimers with BMP2, which can play an important role to regulate cell fate determination (Chang and Hemmati-Brivanlou, 1999).

BMP antagonists secreted by dorsal mesoderm seem sufficient to neuralize the ectoderm. However, it appears that BMP activity must be regulated at additional levels. A level of regulation probably exists during neural induction to reduce the expression of BMP genes in the dorsal ectoderm. BMP4 transcripts are excluded from the dorsal side at gastrula stage (a time when neural induction occurs), including the dorsal ectoderm whose fate is to become the future neural plate (Hemmati-Brivanlou and Thomsen, 1995). However, BMP2 and BMP7 RNAs are expressed in the entire presumptive ectoderm at gastrula stage. In 1998, Kroll et al. have identified Geminin, a new neuralizing molecule. The maternal geminin mRNA is found throughout the animal hemisphere from oocyte through late blastula stage. At early gastrula, its expression is restricted to a dorsal territory corresponding to the future neural plate. In this territory, at this time, the expression of BMP4 is absent. Misexpression of Geminin in gastrula both suppresses the expression of BMP4 and neuralizes the prospective epidermis. It can upregulates the expression of proneural genes such as X-ngr-1. The dominant negative Geminin suppress neural differentiation and when misexpressed in the dorsal ectoderm, it produces islets of epidermal genes expression within the neurectoderm. These effects are rescued by the coexpression of the full-length molecule. Therefore, the role of Geminin in early development is to define the future territory of the neural plate and to downregulate the expression of epidermal inducers (BMPs).

\section{Smad proteins as BMP signal trans- ducers are involved in epidermal de- termination}

It has been reported that BMPs can activate a MAP kinase pathway, leading to apoptosis in Xenopus embryo (Shibuya et al., 1998). However, some evidence shows that the prominent role in BMP signaling is performed by Smads proteins (Dale and Jones, 1999; Heldin et al., 1997), (see Fig. 1). Smads are the substrates for type I recep- tor kinase. They were identified as the products of the Drosophila Mad (mothers against dpp) and Coenorahabditis Sma genes, which act downstream of the BMP homologous ligand receptor in these organisms (Newfeld et al., 1996; Savage et al., 1996; Sekelsky et al., 1995). The vertebrate homologues of Mad and Sma have been cloned and they were designated as Smad for Sma and Mad. At least nine vertebrate homologues have been identified (Smad1-9) (Heldin et al., 1997; Itoh et al., 2000).

The Smad family can be divided into three distinct groups: receptor-regulated Smads (R-Smads which involved Smad 1, 2 , 3, 5, 8; common partner Smads (Co-Smads), with Smad 4 and XSmad $4 \beta$ and inhibitory Smads (I-Smads) with Smads 6,7 (for review see Itoh et al., 2000). Activated type I receptor kinase interacts transiently with the R-Smads and phosphorylates them. The activated R-Smad recruits Co-Smad and the heteromeric complex accumulates in the nucleus. Nuclear Smad complex can bind to DNA directly or indirectly through other DNA binding proteins and regulates the transcription of target genes (Derynck et al., 1998; Massagué and Wotton, 2000). Smad1, Smad5, (and maybe Smad9) mediate BMP signaling during ectodermal patterning. Smad1 has been shown to inhibit neural induction induced by a truncated BMP receptor in intact animal caps and both Smad1 and Smad5 can mimic BMP4 in inhibiting neural formation and inducing epidermal-type keratin in the cell dissociation assay. Smad1, Smad5 and possibly Smad9 are specific signals in the transduction of the BMP pathway (Chen et al., 1997b; Graff et al.,
$A$

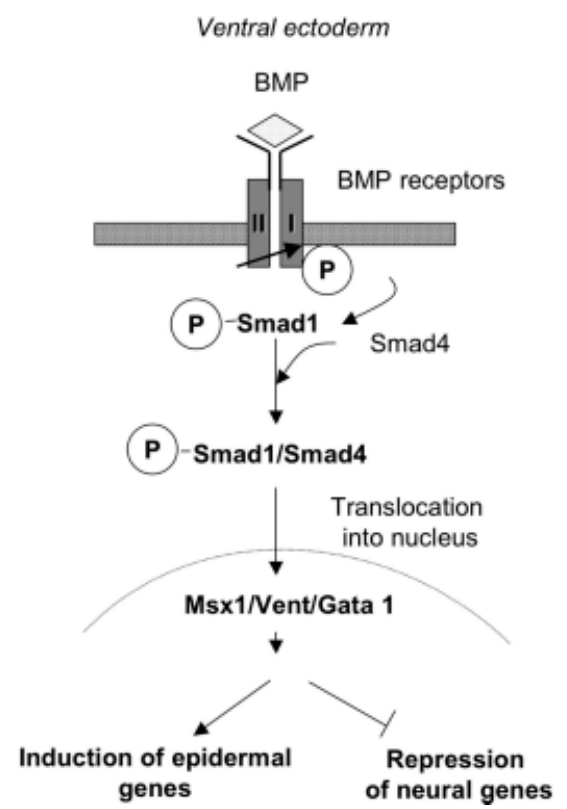

B
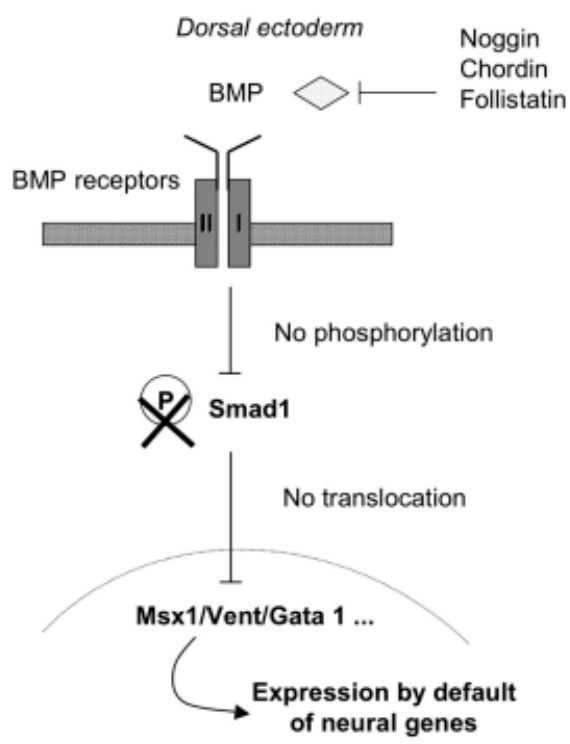

Fig. 1. Model for epidermal and neural inductions in Xenopus laevis embryo. In the case of epidermal induction (Left ), the transduction of BMP pathways leads to the formation of the complex between phosphorylated Smad1 and Smad4, which is translocated into the nucleus. This complex activates DNA binding proteins such as Msx1, which activates epidermal gene expression and represses neural gene transcription. In case of neural induction, (Right) neural inducers such as Noggin prevent the binding of BMPs to its receptors, leading to a blocking of BMP signal transduction. This inhibition of BMP signaling results in a de-repression of neural gene expression. This model known as neuralization by default does not take into account the necessary and sufficient role played by calcium ions, as discussed in this article. 
1996; Suzuki et al., 1997a; Thomsen, 1996; Wilson et al., 1997), The Co-Smad, Smad4, is a partner for the R-Smads. In mammalian cell culture, Smad4 forms a heterodimer with Smad1 upon BMP4 stimulation. In amphibian ectoderm, both Smad1 and Smad5-dependent neural inhibition is blocked by the mutant Smad4 (Suzuki et al., 1997a). Smad6, Smad7, Smad8, (Hata et al., 1998; Hayashi et al., 1997; Imamura et al., 1997; Nakao et al., 1997; Nakayama et al., 1998; Topper et al., 1997; Tsuneizumi et al., 1997) act as inhibitors of TGF- $\beta$ signal transduction. Overexpression of Smad6 or Smad7 is sufficient to induce neural markers in the absence of mesoderm in Xenopus ectodermal cells and the corresponding RNA can induce a partial secondary axis when injected in the ventral side of embryos (Casellas and Hemmati-Brivanlou, 1998; Hata et al., 1998; Nakayama et al., 1998).

Smad7 seems to inhibit all TGF- $\beta$ ligands with no discrimination, such as TGF- $\beta 1$, activin, $\mathrm{Vg} 1$ and BMP4 by a non selective binding to the TGF- $\beta$ type I receptor (Hata et al., 1998; Hayashi et al., 1997). Smad8 preferentially blocks BMP signaling, although it may also be involved in other pathways. In ectodermal determination, inhibitory Smads may play an important role in balancing epidermal and neural induction by blocking activities of Smad1/ Smad5/ Smad9 (Fig. 1).

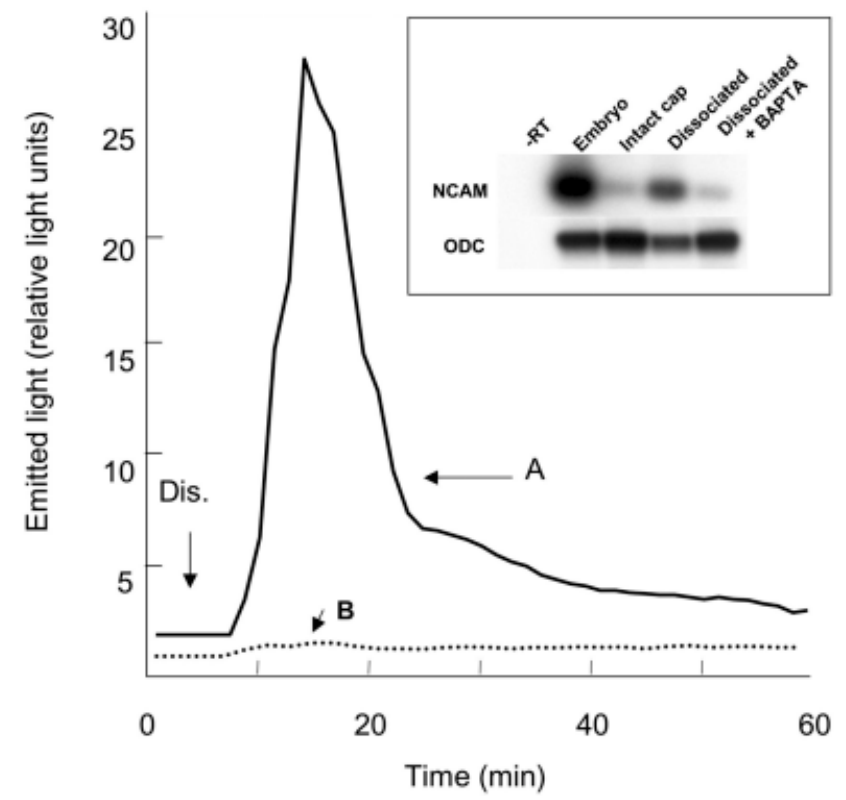

Fig. 2. Recording of internal calcium concentration during dissociation of Xenopus ectodermal cells. Trace A represents concentration in medium free of divalent ions. Trace $B$ is from an experiment performed after loading ectodermal cells with BAPTA-AM $10.4 \mathrm{mM}$ in the external medium). To measure calcium, cells were previously loaded with aequorin as previously described (Leclerc et al., 2001). Inset: expression of the pan-neural marker NCAM in the animal caps was measured by RT-PCR. Dissociated caps differentiated into neural cells expressing NCAM. BAPTA-AM loaded caps before dissociation (Dissociated+BAPTA) show a dramatic reduction in NCAM expression. Intact cap: animal caps not dissociated; sibling control embryos served as positive control (embryo) and PCR on the same RNA without reverse transcription was done to check the absence of genomic DNA (-RT). ODC is the control with ornithine decarboxylase.
Some evidence shows that the Smad complex can bind directly with DNA (Dennler et al., 1998). However in Xenopus it has been shown that the complex Smad 2/Smad 4 binds to Fast 1 a winged helix DNA binding protein. The complex Smad2/Smad4/Fast1 interact with specific sequence on the DNA within the mix2 promoter (Chen etal., 1996; Chen et al., 1997a). For the moment, no such a sequence has been described for the Smad1/Smad4 complex.

\section{Transcriptional regulation of epidermal and neural fates by BMP signaling}

In early Xenopus embryos, a number of genes have been identified that are transcriptionaly regulated in response to BMP signaling. These include homeobox proteins $\mathrm{Xms} \times 1$, mix1, Xhox3, Xfd1 and Xmyf5, the intracellular signaling molecule XSmad8 and the intercellular signaling molecules Xwnt8 and XBMP4 (Dale and Jones, 1999) and a new family of homeobox transcription factors such as Xvent-1, Xvent-2 (also known as Xom) (Gawantka et al., 1995; Ladher et al., 1996; Onichtchouk et al., 1996). All these genes can be upregulated by BMP4 and the overexpression of these factors in Xenopus results in ventralized phenotypes (i.e. promote epidermal differentiation at the expense of neural structures), as does BMP4 (Chang and Hemmati-Brivanlou, 1998 for a review). The expression is blocked by the inhibitors of BMP 4 signaling such as dominant negative type I BMP receptors. Expression of dominant negative constructs of Xvent-1, Xvent-2 and Xmsx1, inhibit epidermal determination and neuralize the isolated ectoderms. Xms 1 and Xvent2 are activated in absence of protein synthesis and certainly represent immediate early response to BMP4 signaling (Ladher et al., 1996; Suzuki et al., 1997c).

Neural plate-specific markers (expressed both in neurons and glia), such as NCAM, can be activated in the animal caps by zinc finger transcription factors of the Zic family (Zic3; Zicrelated-1) (Mizuseki et al., 1998; Nakata et al., 1997) or by a POU domain-containing DNA binding factor, XIPou2 (Witta et al., 1995). Zic3, Zic-r1 and XIPou2 are expressed in the neurectoderm at gastrula stages, suggesting that they may participate in neural induction in vivo. In addition, these genes are induced by BMP antagonists (Noggin and Chordin) and suppressed by BMP4. However, the mechanism which regulates their expression in the ectoderm remains to be found. Xvents genes have been reported to behave as repressors of transcription (Friedle et al., 1998; Trindade et al., 1999). A consensus Xvent-2 DNA-binding site has been identified. Furthermore, the goosecoid promoter contains a sequence which is required for the Xvent- 2 mediated repression of this homeobox gene (Trindade et al., 1999).

This suggests that in ectodermal cells, BMP-regulated DNAbinding proteins, such as Xvents or Xmsx1, may repress expression of neural-specific transcription activators to block neural commitment. Alternatively, BMP-dependent transcription factors may suppress neural gene expression directly by blocking access of neural-specific activators to DNA.

Altogether, these results suggest that the determination of the epidermal and neural cell fates may rely on the balanced interaction of the opposing transcription factors. In the absence of BMP signals, neural inhibitory transcription factors are ren- 
dered inactive, whereas neural genes are activated by DNA-binding proteins i.e. Zic3, Zic-r1 or XIPOU2.

\section{Calcium is involved in the choice be- tween neural and epidermal fate}

Data obtained in the last ten years suggest that the choice of fate of the ectoderm results from an antagonism, at extracellular level, between ventralizing signals (Bone Morphogenetic proteins, BMP 2,4,7) and dorsalizing signals secreted by the dorsal mesoderm (Noggin, Chordin, Follistatin, XnR3, Cerberus...). Mechanisms involved in specifying the fate of the ectoderm suggest that the epidermal induction results from the activation of a transduction cascade and have been therefore defined as an instructive process involving the binding of BMPs on their receptors (Fig. 1). This cascade has two effects: it induces epidermis and inhibits neural fate. On the contrary, neuralization would simply results from the inhibition of the instructive process and is therefore regarded as a permissive process (for review see Weinstein and Hemmati-Brivanlou, 1999).

If the by default model has allowed to understand a part of the processes of early neurogenesis and epidermal determination at the molecular level, a number of important questions remain to be resolved. In particular, what is the transduction cascade involved between plasma membrane and nucleus (downstream of Noggin and BMP) which leads to the neural fate. Indeed, the default model hardly explains the inhibition of the neuralization triggered by Noggin on isolated ectoderms which express truncated forms of FGF receptors (Launay et al., 1996). We have identified several elements belonging to the transduction of the neuralizing signal, which allows us to ask the question: is neural determination really a by default process?

Several old works have shown that calcium might play an important role in the choice of determination (neural vs epidermal). Barth and Barth, (1964) have suggested that calcium is important to trigger neuralization in Rana pipiens ectoderm. Patch clamp experiments performed in our laboratory have shown that calcium permeability intervenes during gastrulation (unpublished results). Moreover, it is well known that dissociation of animal caps in divalent ions free medium orientated the cells toward a neural fate (Godsave and Slack, 1989; Grunz and Tacke, 1989; Saint-Jeannet et al., 1990; Sato and Sargent, 1989).

\section{Neuralization by dissociation of ectodermal cells is associated with a calcium signal}

Neuralization by dissociation can be explained by the dilution of epidermal inductors (BMPs) from the receptors. However we have shown that the dissociation of animal caps in calcium free medium triggers an increase in intracellular calcium concentration $\left[\mathrm{Ca}^{2+}\right.$. (Fig. 2). This increase is probably due to an efflux of calcium from internal stores resulting from the inversion of the calcium gradient of concentration between intra and extracellular compartments (Leclerc et al., 2001). When ectodermal cells are loaded with the calcium chelator BAPTA, neuralization by disso- ciation was inhibited and the neural marker NCAM is not expressed (Leclerc et al., 2001). This suggests that a dilution of epidermal inducers is not sufficient to explain the results. A calcium dependent signal appears to be required to trigger the neuralization of the ectoderm and consequently, to inhibit epidermal fate.

\section{Noggin triggers an increase in intracellular calcium concentration}

The isolated ectoderm follows epidermis fate in absence of inductive signals. In the presence of an inductive signal such as Noggin, it will adopt a neural fate. Addition of Noggin on isolated ectoderms triggers an increase in $\left[\mathrm{Ca}^{2+}\right]$. This increase has 10-20 minutes duration and represents about $15 \%$ of the resting level of $\left[\mathrm{Ca}^{2+}\right]$. (Moreau et al., 1994). This increase is totally inhibited by L-type channel antagonists, such as nifedipine or nimodipine. In addition, the blockade of L-type calcium channels inhibits neural induction (Leclerc et al., 1997). It is not excluded that other sources of calcium may be involved, at least partially. In fact methylxanthines such as caffeine or theophyline, known to release calcium from internal stores, are potent neural inducers (Moreau et al., 1994).

\section{Direct activation of L-type calcium channels triggers neural induction on isolated ectoderms}

The isolated ectoderm directly stimulated by specific agonists of L-type calcium channels (S(-)Bay K 8644) presents a transient increase in $\left[\mathrm{Ca}^{2+}\right]$ of 20 minutes duration. This transient increase is sufficient, even in an active BMP context, to trigger neural induction. The treated ectoderm cells differentiate in neural and glial cells, which can be characterized by immunocytochemistry (Moreau et al., 1994) (Fig. 3).

All the previous results have been obtained on animal caps, which is an in vitro system. However, we have confirmed that during gastrulation, calcium dependent phenomenon also occurs in a whole embryo. We have visualized calcium movements in each cell of the dorsal ectoderm in a whole Xenopus embryo during gastrulation using the photoprotein aequorine and a new 
Fig. 4. An example of a sequence of $\mathrm{Ca}^{2+}$ transients which occur in the dorsal ectoderm from a representative embryo at stage 11.5 (12 hours post fertilization). Each aequorin-generated photon image represents $120 \mathrm{sec}$ onds of accumulated light and is superimposed on its corresponding image of the embryo. These images show the different intensities of tran-

A

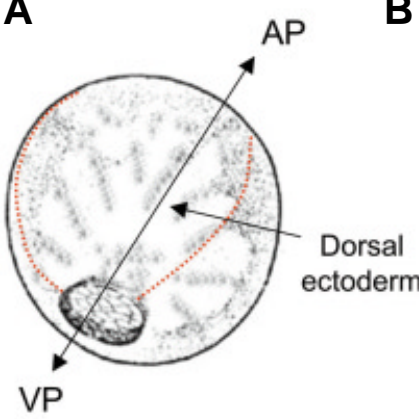

B
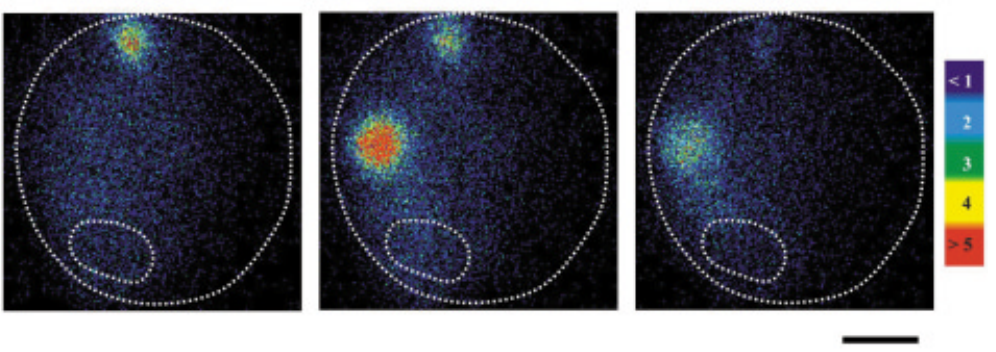

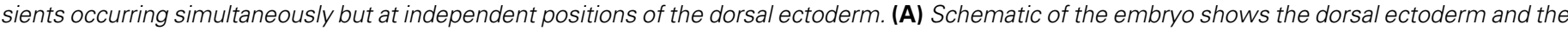
antero-posterior axis. AP, animal pole; VP, vegetal pole. Color scale indicates luminescent flux in photon per pixel. Scale bar, $0.3 \mathrm{~mm}$.

technique of $\mathrm{Ca}^{2+}$ imaging system which has a high sensitivity (Miller et al., 1994). This technique allows visualizing calcium movements in the whole embryo (Fig. 4). The onset of calcium signaling activity occurs at late blastula stage (stage 8-9), at a time when zygotic transcription starts. As gastrulation proceeds, calcium flashes increase both in number and intensity, to reach a peak activity by mid-gastrulation (stage 11-11.5), a stage where neural determination is thought to have occurred. This activity was found strictly restricted to dorsal ectoderm (the tissue where neural induction takes place) and never occurs in ventral ectoderm cells, which are at the origin of epidermis. Ventral cells never receive neural inductive signals.

The increase in $\left[\mathrm{Ca}^{2+}\right]$ is determinant since neural induction was totally blocked in ectoderm cells preloaded with the potent calcium chelator BAPTA or if specific antagonists of L-type calcium channels blocked $\mathrm{Ca}^{2+}$ channels. In these last conditions the embryos lack anterior brain structures (Leclerc et al., 1997; Leclerc et al., 2001; Moreau et al., 1994), (Fig. 5).

Our results suggest that the increase in $\left[\mathrm{Ca}^{2+}\right]$ occurring during neural induction in dorsal ectoderm creates calcium compartments of high level. These compartments can activate transcription factors that have a proneural activity.

\section{Calcium targets}

To understand how the $\left[\mathrm{Ca}^{2+}\right]$ can control neural determination, we have to determine the elements, which belong to the excitationtranscription coupling (reception of Noggin signal/neural genes expression). We have shown that calcium controls the expression of c-fos (Leclerc etal., 1999) and at least two other transcription factors: XIPou2 and Zic3. If Fos is a ubiquitous transcription factor, XIPou2 and Zic3 are specific of neural determination. They belong respectively to the POU domain family and odd-paired domain family of transcription factors (Nakata etal., 1997; Witta etal., 1995). They are primary neural regulators and we have found that their expression is calcium dependent. Indeed, our experiments performed on isolated Xenopus ectoderms show that XIPou2 is induced very early after an increase in $\left[\mathrm{Ca}^{2+}\right]$. The mRNA for XIPou2 is detectable as early as 30 minutes after $\left[\mathrm{Ca}^{2+}\right]$ increase. In addition, specific antagonists of L-type calcium channels block the expression of XIPou2 in response to Noggin. The expression of Zic3 is dramatically reduced when the embryos are incubated in presence of antagonists of L-type calcium channels (Leclerc et al., 2000).

\section{Neural competence of the ectoderm is linked to the expression of L-type calcium channels}

The ability of the ectodermal cells to be induced and to differentiate toward neural tissue in response to signals coming from the mesoderm is called neural competence. This competence is acquired shortly before gastrulation and lost during late gastrula stages in amphibian embryos. Both protein kinase $\mathrm{C}$ (PKC) and G-protein pathways have been proposed to affect the ectoderm competence (Otte et al., 1991; Otte et al., 1992; Otte and Moon, 1992; Pituello et al., 1991). However, PKC or G protein alone are unable to induce neural tissue. We have demonstrated that the appearance of dihydropyridine sensitive calcium channels (L-type $\mathrm{Ca}^{2+}$ channels) is correlated with the acquisition of neural competence by the ectodermal cells. The highest density of these channels is reached when competence of the ectoderm is optimal. Conversely, the decrease of L-type $\mathrm{Ca}^{2+}$ channel density occurs simultaneously with the normal loss of competence. In addition, we show that these channels are functional. We propose that the molecular basis of the gain and loss of neural competence is linked to the presence of L-type $\mathrm{Ca}^{2+}$ channels in ectodermal cell membranes of amphibian embryos (Dréan et al., 1995; Leclerc et al., 1995).

\section{Control of the choice of determination: a new model}

Our results show that an increase in $\left[\mathrm{Ca}^{2+}\right]$ is a necessary and sufficient event to turn the fate of ectoderm cells from epidermis to neural tissue. However, one of the important unresolved questions raised by our data, concerns the mechanism by which the L-type $\mathrm{Ca}^{2+}$ channels are activated during gastrulation in the dorsal ectoderm. This question is linked to an other one: how Noggin may produce an influx of $\mathrm{Ca}^{2+}$ through L-type $\mathrm{Ca}^{2+}$ channels? In this respect, it is interesting to further consider the relation between Noggin and the FGF receptor. On animal caps, it has been shown that truncated FGF receptor prevents neuralization triggered by the BMP antagonist, Noggin (Launay et al., 1996). We think that FGF receptor might be implied in the transduction of this signal via the activation of calcium dependent pathways. Indeed, during mesoderm induction FGF produces the phosphorylation of a phospholipase (PLC $\gamma)$, which in turn activates a protein kinase C (PKC) (Gillespie et al., 1992). Activation of PKC by phorbolesters has been shown to cause neural differ- 
entiation in Xenopus dorsal ectoderm (Otte et al., 1991) and to triggers an increase in internal calcium concentration associated with neural induction on isolated ectoderms of the amphibian Pleurodeles. This increase in internal concentration is due to the activation of L-type calcium channels (Moreau et al., 1994). Furthermore, on chick embryo neurons, activation of the FGF receptor leads to membrane potential depolarization, which causes $\mathrm{Ca}^{2+}$ influx through voltage, operated $\mathrm{Ca}^{2+}$ channels (Distasi et al., 1995). It will be interesting to test whether the suppression of the BMP pathway by Noggin is associated with a change in membrane potential.

It is important to emphasize that a $\mathrm{Ca}^{2+}$ increase is sufficient to induce neural tissue even in an active BMP context. This suggests that calcium participates in the inhibition of the BMP pathway and leads us to propose a new model (Fig. 6) to explain what prompts a cell to select an epidermal versus a neuronal pathway. This model involved the activation by calcium of specific kinases and phosphatases. The action of BMP antagonists (i.e. Noggin, Chordin) is one way to inhibit BMP signaling by preventing BMP4 to interact with its receptor; it is so far the most studied way. However, an other way is to act downstream and to block either BMP receptor activation or Smad phosphorylation. It is reported that the spatial distribution of activated Smad1 (phosphorylated Smad1) changes at the onset of gastrulation. Prior to gastrulation, phosphorylated Smad1 is equally distributed between dorsal and ventral side of the embryo, reflecting activation of the BMP4 signaling pathway, whereas at stage 9.5 , Smad1 phosphorylation is enriched in the ventral side and by stage 10.25 (early gastrulation) most of the activated Smad1 is localized to the ventral side (Faure et al., 2000). This result correlates with the pattern of calcium increase which starts in dorsal ectoderm at stage 9 and is maximum by stage 11.5 (mid-gastrulation) (Leclerc et al., 2000). Xenopus calcineurin, a $\mathrm{Ca}^{2+} /{ }^{2}$ calmodulin dependent phosphatase $2 \mathrm{~B}$, has been cloned. It is $94 \%$ identical at the amino acid level with the murin and human calcineurin. It is expressed through out early development (Saneyoshi et al., 2000). One can hypothesized that dephosphorylation of Smad1 in the dorsal ectoderm during gastrulation is controlled by calcineurin.

FKBP, a cytosolic protein that binds the calcium dependent protein phosphatase calcineurin, appears to inhibit BMP4 signaling in Xenopus embryos. Injection of FKBP mRNA into 8-cell stage embryos generates the formation of ectopic axis. No secondary axis formation occurs when FKBP was coinjected with Smad1, a downstream signaling molecule of BMP4 receptor. This effect is probably mediated by calcineurin since injection of constitutively active murin calcineurin produces a similar phenotype. Furthermore, a FKBP mutant unable to bind calcineurin did not induced ectopic axis (Nishinakamura et al., 1997).

Taken together these lines of evidence suggest that the increase in intracellular calcium recorded during gastrulation may activates the calcium dependent protein phosphatase calcineurin, which in turn will block BMP4 signaling. As a consequence of this inhibition, ectoderm will adopt a neural instead of an epidermal fate.

The activation of calcium calmodulin kinase II (CaMkinase II) has been reported to occurs during the transcriptional activation of immediate early gene such as c-fos (Greenberg et al., 1992). In isolated ectoderm from the newt Pleurodeles walt, a Fosrelated protein is upregulated during neural induction. This is triggered by Noggin and involves an increase in intracellular calcium mediated by the activation of L-type $\mathrm{Ca}^{2+}$ channels. The expression of this Fos-related protein is dependent on the activation of a CaMkinase, blocked by KN62, which in turn phosphorylates the $\mathrm{Ca}^{2+} / \mathrm{CAMP}$ response element binding protein (CREB) (Leclerc et al., 1999). Future considerations will include identifying downstream targets of calcium and $\mathrm{Ca}^{2+}$ response element on promoters of early neural-specific transcription factors.

The model (Fig. 6) for the choice of determination (epidermal vs neural) involves two instructive mechanisms; an instructive mechanism (epidermal determination) and a permissive mechanism (neu-
A

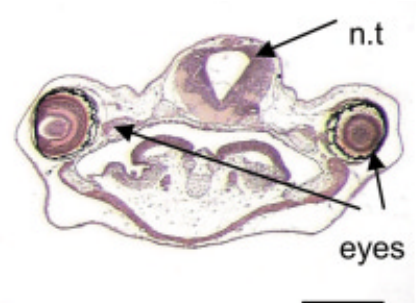

B

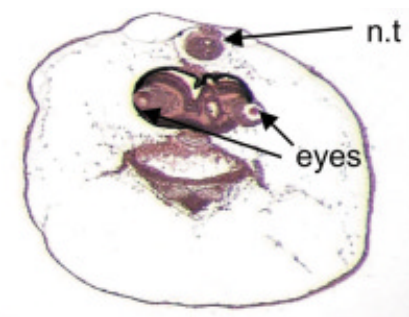

Fig. 5 (Left). Transverse section of the head of a Xenopus embryo (stage 42, 3 days) stained with hematoxylin-eosin. (A) Control embryo. (B) Embryo incubated in the presence of nifedipine $10 \mu \mathrm{M}$ (L-type calcium channels antagonist). n.t, neural tube; bar, $100 \mu \mathrm{m}$.

Fig. 6 (Right). New model for neural induction in Xenopus laevis embryo. In this model, calcium plays the central role, by activating a calcineurin which prevent the phosphorylation of the Smads and by the control of neural gene transcription, either directly or via the activation of a calcium calmodulin kinase type II (CaMK II) (see text for more details).

L-type calcium channels are activated by unidentified mechanisms at the level of the binding of BMP by neural inducers. Under these conditions, neuralization is not a permissive process, but an instructive mechanism as epidermal induction.

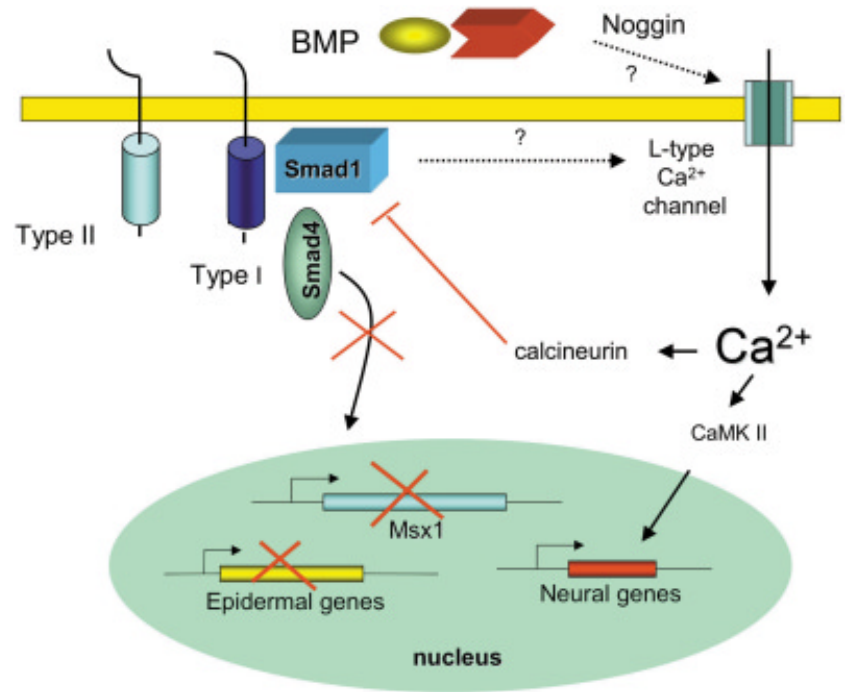


ral determination). Neural determination requires numerous BMP4 signaling inhibitors both outside (Noggin, Chordin...) and inside the cell (calcium). In this model, calcium is a central regulator that inhibits BMP signaling pathways (epidermal determination) and activates neural pathway. The instructive mechanism involved in epidermal induction is well known, but the model we propose for neural induction remains to be analyzed in details.

\section{Summary}

The development of the vertebrate embryo, which includes the induction and the patterning of the three germ layers requires signaling among cells. In vertebrates, during gastrulation, the cells of the embryonic ectoderm have the choice between to fates; they give rise to epidermal progenitors on the ventral side and neural progenitors in the dorsal side. It was first shown by Spemann and Mangold in 1924 that the dorsal mesoderm (also called the Spemann-Mangold Organizer; see Sander and Faessler, 2001) has the potent biological activity to induce nervous system from the adjacent ectoderm. A similar observation was reported in amniotes, indicating that the neural induction by the organizer is a conserved process controlling the initial step in vertebrates neurogenesis. Molecular studies of the last decade have led to the identification of signaling molecules that participate in these embryonic decisions. Epidermis induction occurs through a signaling cascade involving Bone Morphogenetic Proteins (BMP 2, $4,7)$ and receptor-regulated Smad proteins which translocate into the nucleus to form active transcriptional complexes. These molecules mediate BMPs effect to activate epidermal-specific gene expression and to repress neural-specific gene transcription. The neural fate is revealed by factors secreted by the dorsal mesoderm (Noggin, Chordin, Follistatin, ...) which act by blocking BMP signaling. Consequently, epidermal fate is an induced fate while neural fate is interpreted as a default state of the ectoderm. Here, we discuss an alternative where neural fate is not a default state; this new model integrates the activation of a calciumdependent signaling pathway due to an influx of calcium through L-type calcium channel. In this model, calcium plays a central regulatory role. While calcium is required for neural determination, epidermal determination occurs when calcium-dependent signaling pathways are inactive.

\section{Acknowledgements}

We thank Drs A. Miller and S. Webb in HKUST (Hong Kong) for fruitful collaboration and discussions on calcium imaging. This work was supported by the joint CNRS/HKRGC PROCORE program; Centre National de la Recherche Scientifique (CNRS), Association pour la Recherche contre le Cancer (ARC), HK Research Grants Council.

\section{References}

BARTH, L. G. and BARTH, L. J. (1964). Sequential induction of the presumptive epidermis of the Rana pipiens gastrula. Biol.Bull. 127, 413-427.

BEDDINGTON, R. S. (1994). Induction of a second neural axis by the mouse node. Development 120, 613-20.

BOUWMEESTER, T., KIM, S., SASAI, Y., LU, B. and DE ROBERTIS, E. M. (1996). Cerberus is a head-inducing secreted factor expressed in the anterior endoderm of Spemann's organizer. Nature 382, 595-601.

CASELLAS, R. and HEMMATI-BRIVANLOU, A. (1998). Smad7 inhibits both activin and BMP pathways and acts as a neural inducer. Dev. Biol. 198, 1-12.
CHANG, C. and HEMMATI-BRIVANLOU, A. (1998). Cell fate determination in embryonic ectoderm. J Neurobio/36, 128-51.

CHANG, C. and HEMMATI-BRIVANLOU, A. (1999). Xenopus GDF6, a new antagonist of noggin and a partner of BMPs. Development 126, 3347-57.

CHEN, X., RUBOCK, M. J. and WHITMAN, M. (1996). A transcriptional partner for MAD proteins in TGF-beta signalling. Nature 383, 691-6.

CHEN, X., WEISBERG, E., FRIDMACHER, V., WATANABE, M., NACO, G. and WHITMAN, M. (1997a). Smad4 and FAST-1 in the assembly of activin-responsive factor. Nature 389, 85-9.

CHEN, Y., BHUSHAN, A. and VALE, W. (1997b). Smad8 mediates the signaling of the receptor serine kinase. Proc Nat/ Acad Sci U S A 94, 12938-43.

COX, W. G. and HEMMATI-BRIVANLOU, A. (1995). Caudalization of neural fate by tissue recombination and bFGF. Development 121, 4349-58.

DALE, L. and JONES, C. M. (1999). BMP signalling in early Xenopus development. Bioessays 21, 751-60.

DENNLER, S., ITOH, S., VIVIEN, D., TEN DIJKE, P., HUET, S. and GAUTHIER, J. M. (1998). Direct binding of Smad3 and Smad4 to critical TGF-beta-inducible elements in the promoter of human plasminogen activator inhibitor-type 1 gene. Embo J17, 3091-100.

DERYNCK, R., ZHANG, Y. and FENG, X. H. (1998). Smads: transcriptional activators of TGF-beta responses. Cel/95, 737-40.

DISTASI, C., MUNARON, L., LAEZZA, F. and LOVISOLO, D. (1995). Basic fibroblast growth factor opens calcium-permeable channels in quail mesencephalic neural crest neurons. Eur J Neurosci7, 516-20.

DREAN, G., LECLERC, C., DUPRAT, A. M. and MOREAU, M. (1995). Expression of L-type $\mathrm{Ca}^{2+}$ channel during early embryogenesis in Xenopus laevis. Int J Dev Bio/39, 1027-32.

FAINSOD, A., DEISSLER, K., YELIN, R., MAROM, K., EPSTEIN, M., PILLEMER, G., STEINBEISSER, H. and BLUM, M. (1997). The dorsalizing and neural inducing gene follistatin is an antagonist of BMP-4. Mech Dev63, 39-50.

FAURE, S., LEE, M. A., KELLER, T., TEN DIJKE, P. and WHITMAN, M. (2000). Endogenous patterns of TGFbeta superfamily signaling during early Xenopus development. Development 127, 2917-31.

FRIEDLE, H., RASTEGAR, S., PAUL, H., KAUFMANN, E. and KNOCHEL, W. (1998). Xvent-1 mediates BMP-4-induced suppression of the dorsal-lip-specific early response gene XFD-1' in Xenopus embryos. EMBO J17, 2298-307.

GAWANTKA, V., DELIUS, H., HIRSCHFELD, K., BLUMENSTOCK, C. and NIEHRS, C. (1995). Antagonizing the Spemann organizer: role of the homeobox gene Xvent-1. Embo J14, 6268-79.

GILBERT, S. F. and SAXEN, L. (1993). Spemann's organizer: models and molecules. Mech Dev 41, 73-89.

GILLESPIE, L. L., PATERNO, G. D., MAHADEVAN, L. C. and SLACK, J. M. (1992). Intracellular signalling pathways involved in mesoderm induction by FGF. Mech Dev 38, 99-107.

GODSAVE, S. F. and SLACK, J. M. (1989). Clonal analysis of mesoderm induction in Xenopus laevis. Dev Biol 134, 486-90.

GRAFF, J. M., BANSAL, A. and MELTON, D. A. (1996). Xenopus Mad proteins transduce distinct subsets of signals for the TGF beta superfamily. Ce//85, 479-87.

GREENBERG, M. E., THOMPSON, M. A. and SHENG, M. (1992). Calcium regulation of immediate early gene transcription. J Physiol Paris 86, 99-108.

GRUNZ, H. and TACKE, L. (1989). Neural differentiation of Xenopus laevis ectoderm takes place after disaggregation and delayed reaggregation without inducer. Cell Differ Dev28, 211-7.

HAMBURGER, V. (1988). The heritage of experimental embryology: Hans Spemann and the organizer. Oxford University Press, Oxford.

HANSEN, C. S., MARION, C. D., STEELE, K., GEORGE, S. and SMITH, W. C. (1997). Direct neural induction and selective inhibition of mesoderm and epidermis inducers by Xnr3. Development 124, 483-92.

HATA, A., LAGNA, G., MASSAGUE, J. and HEMMATI-BRIVANLOU, A. (1998), Smad6 inhibits BMP/Smad1 signaling by specifically competing with the Smad4 tumor suppressor. Genes Dev 12, 186-97.

HAWLEY, S. H., WUNNENBERG-STAPLETON, K., HASHIMOTO, C., LAURENT, M. N., WATABE, T., BLUMBERG, B. W. and CHO, K. W. (1995). Disruption of BMP signals in embryonic Xenopus ectoderm leads to direct neural induction. Genes Dev 9, 2923-35. 
HAYASHI, H., ABDOLLAH, S., QIU, Y., CAI, J., XU, Y. Y., GRINNELL, B. W., RICHARDSON, M. A., TOPPER, J. N., GIMBRONE, M. A., JR., WRANA, J. L. and FALB, D. (1997). The MAD-related protein Smad7 associates with the TGFbeta receptor and functions as an antagonist of TGFbeta signaling. Cel/89, 1165-73.

HELDIN, C. H., MIYAZONO, K. and TEN DIJKE, P. (1997). TGF-beta signalling from cell membrane to nucleus through SMAD proteins. Nature 390, 465-71.

HEMMATI-BRIVANLOU, A., KELLY, O. G. and MELTON, D. A. (1994). Follistatin, an antagonist of activin, is expressed in the Spemann organizer and displays direct neuralizing activity. Cel/77, 283-95.

HEMMATI-BRIVANLOU, A. and MELTON, D. A. (1992). A truncated activin receptor inhibits mesoderm induction and formation of axial structures in Xenopus embryos. Nature 359, 609-14.

HEMMATI-BRIVANLOU, A. and MELTON, D. A. (1994). Inhibition of activin receptor signaling promotes neuralization in Xenopus. Cel/77, 273-81.

HEMMATI-BRIVANLOU, A. and THOMSEN, G. H. (1995). Ventral mesodermal patterning in Xenopus embryos: expression patterns and activities of BMP-2 and BMP-4. Dev Genet 17, 78-89.

IEMURA, S., YAMAMOTO, T. S., TAKAGI, C., KOBAYASHI, H. and UENO, N. (1999). Isolation and characterization of bone morphogenetic protein-binding proteins from the early Xenopus embryo. J Biol Chem 274, 26843-9.

IMAMURA, T., TAKASE, M., NISHIHARA, A., OEDA, E., HANAI, J., KAWABATA, M. and MIYAZONO, K. (1997). Smad6 inhibits signalling by the TGF-beta superfamily. Nature 389, 622-6.

ITOH, S., ITOH, F., GOUMANS, M. J. and TEN DIJKE, P. (2000). Signaling of transforming growth factor-beta family members through Smad proteins. EurJ Biochem 267, 6954-67.

KENGAKU, M. and OKAMOTO, H. (1995). bFGF as a possible morphogen for the anteroposterior axis of the central nervous system in Xenopus. Development 121, 3121-30.

KROLL, K. L. and AMAYA, E. (1996). Transgenic Xenopus embryos from sperm nuclear transplantations reveal FGF signaling requirements during gastrulation. Development 122, 3173-83.

KROLL, K. L., SALIC, A. N., EVANS, L. M. and KIRSCHNER, M. W. (1998). Geminin, a neuralizing molecule that demarcates the future neural plate at the onset of gastrulation. Development 125, 3247-58.

LADHER, R., MOHUN, T. J., SMITH, J. C. and SNAPE, A. M. (1996). Xom: a Xenopus homeobox gene that mediates the early effects of BMP-4. Development 122, 2385-94.

LAMB, T. M. and HARLAND, R. M. (1995). Fibroblast growth factor is a direct neural inducer, which combined with noggin generates anterior-posterior neural pattern. Development 121, 3627-36.

LAMB, T. M., KNECHT, A. K., SMITH, W. C., STACHEL, S. E., ECONOMIDES, A. N., STAHL, N., YANCOPOLOUS, G. D and HARLAND, R. M. (1993). Neural induction by the secreted polypeptide noggin. Science 262, 713-8.

LAUNAY, C., FROMENTOUX, V., SHI, D. L. and BOUCAUT, J. C. (1996). A truncated FGF receptor blocks neural induction by endogenous Xenopus inducers. Development 122, 869-80.

LECLERC, C., DAGUZAN, C., NICOLAS, M. T., CHABRET, C., DUPRAT, A. M. and MOREAU, M. (1997). L-type calcium channel activation controls the in vivo transduction of the neuralizing signal in the amphibian embryos. Mech Dev64, 105-10.

LECLERC, C., DUPRAT, A. M. and MOREAU, M. (1995). In vivolabelling of L-type $\mathrm{Ca}^{2+}$ channels by fluorescent dihydropyridine: correlation between ontogenesis of the channels and the acquisition of neural competence in ecotderm cells from Pleurodeles waltl embryos. Cell Calcium 17, 216-24.

LECLERC, C., DUPRAT, A. M. and MOREAU, M. (1999). Noggin upregulates Fos expression by a calcium-mediated pathway in amphibian embryos. Dev Growth Differ 41, 227-38.

LECLERC, C., RIZZO, C., DAGUZAN, C., NEANT, I., BATUT, J., AUGE, B. and MOREAU, M. (2001). Neural determination in Xenopus laevis embryos: control of early neural gene expression by calcium. J Soc Bio/195, 327-37.

LECLERC, C., WEBB, S. E., DAGUZAN, C., MOREAU, M. and MILLER, A. L. (2000). Imaging patterns of calcium transients during neural induction in Xenopus laevis embryos. J Cell Sci113 Pt 19, 3519-29.

MASSAGUÉ, J. and WOTTON, D. (2000). Transcriptional control by the TGF-beta/ Smad signaling system. Embo J19, 1745-54.
MILLER, A. L., KARPLUS, E. and JAFFE, L. F. (1994). Imaging $\left[\mathrm{Ca}^{2+}\right]_{i}$ with aequorin using a photon imaging detector. Methods Ce// Bio/40, 305-38.

MIZUSEKI, K., KISHI, M., MATSUI, M., NAKANISHI, S. and SASAI, Y. (1998). Xenopus Zic-related-1 and Sox-2, two factors induced by chordin, have distinct activities in the initiation of neural induction. Development 125, 579-87.

MOREAU, M., LECLERC, C., GUALANDRIS-PARISOT, L. and DUPRAT, A.-M. (1994). Increased internal $\mathrm{Ca}^{2+}$ mediates neural induction in the amphibian embryo. Proc. Natl. Acad. Sci. USA 91, 12639-12643.

NAKAO, A., AFRAKHTE, M., MOREN, A., NAKAYAMA, T., CHRISTIAN, J. L., HEUCHEL, R., ITOH, S., KAWABATA, M., HELDIN, N. E., HELDIN, C. H. and TEN DIJKE, P. (1997). Identification of Smad7, a TGFbeta-inducible antagonist of TGF-beta signalling. Nature 389, 631-5.

NAKATA, K., NAGAI, T., ARUGA, J. and MIKOSHIBA, K. (1997). Xenopus Zic3, a primary regulator both in neural and neural crest developement. pnas 94 , 11980-11985.

NAKAYAMA, T., GARDNER, H., BERG, L. K. and CHRISTIAN, J. L. (1998). Smad6 functions as an intracellular antagonist of some TGF-beta family members during Xenopus embryogenesis. Genes Cells 3, 387-94.

NEWFELD, S. J., CHARTOFF, E. H., GRAFF, J. M., MELTON, D. A. and GELBART, W. M. (1996). Mothers against dpp encodes a conserved cytoplasmic protein required in DPP/TGF-beta responsive cells. Development 122, 2099-108.

NISHINAKAMURA, R., MATSUMOTO, Y., UOCHI, T., ASASHIMA, M. and YOKOTA, T. (1997). Xenopus FK 506-binding protein homolog induces a secondary axis in frog embryos, which is inhibited by coexisting BMP 4 signaling. Biochem Biophys Res Commun 239, 585-91.

ONICHTCHOUK, D., GAWANTKA, V., DOSCH, R., DELIUS, H., HIRSCHFELD, K., BLUMENSTOCK, C. and NIEHRS, C. (1996). The Xvent-2 homeobox gene is part of the BMP-4 signalling pathway controlling dorsoventral patterning of Xenopus mesoderm. Development 122, 3045-53.

OTTE, A. P., KRAMER, I. M. and DURSTON, A. J. (1991). Protein kinase C. and regulation of the local competence of Xenopus ectoderm. Science 251, 570-3.

OTTE, A. P., MCGREW, L. L., OLATE, J., NATHANSON, N. M. and MOON, R. T. (1992). Expression and potential functions of G-protein alpha subunits in embryos of Xenopus laevis. Development 116, 141-6.

OTTE, A. P. and MOON, R. T. (1992). Protein kinase $C$ isozymes have distinct roles in neural induction and competence in Xenopus. Cel/68, 1021-9.

PICCOLO, S., SASAI, Y., LU, B. and DE ROBERTIS, E. M. (1996). Dorsoventral patterning in Xenopus: inhibition of ventral signals by direct binding of chordin to BMP-4. Cel/86, 589-98.

PITUELLO, F., HOMBURGER, V., SAINT-JEANNET, J. P., AUDIGIER, Y. BOCKAERT, J. and DUPRAT, A. M. (1991). Expression of the guanine nucleotide-binding protein Go correlates with the state of neural competence in the amphibian embryo. Dev Bio/145, 311-22.

SAINT-JEANNET, J. P., HUANG, S. and DUPRAT, A. M. (1990). Modulation of neural commitment by changes in target cell contacts in Pleurodeles waltl. Dev Biol141, 93-103.

SANDER, K. and FAESSLER, P.E. (2001). Introducing the Spemann-Mangold organizer: experiments and insights that generated a key concept in develop mental biology. Int. J. Dev. Biol. 45: 1-11.

SANEYOSHI, T., KUME, S., NATSUME, T. and MIKOSHIBA, K. (2000). Molecular cloning and expression profile of Xenopus calcineurin A subunit(1). Biochim Biophys Acta 1499, 164-170.

SASAI, Y., LU, B., STEINBEISSER, H. and DE ROBERTIS, E. M. (1995). Regulation of neural induction by the Chd and Bmp-4 antagonistic patterning signals in Xenopus. Nature 376, 333-6.

SASAI, Y., LU, B., STEINBEISSER, H., GEISSERT, D., GONT, L. K. and DE ROBERTIS, E. M. (1994). Xenopuschordin: a novel dorsalizing factor activated by organizer- specific homeobox genes. Cel/79, 779-90.

SATO, S. M. and SARGENT, T. D. (1989). Development of neural inducing capacity in dissociated Xenopus embryos. Dev Bio/ 134, 263-6.

SAVAGE, C., DAS, P., FINELLI, A. L., TOWNSEND, S. R., SUN, C. Y., BAIRD, S. E. and PADGETT, R. W. (1996). Caenorhabditis elegans genes sma-2, sma3and sma-4 define a conserved family of transforming growth factor beta pathway components. Proc Natl Acad Sci U S A 93, 790-4.

SEKELSKY, J. J., NEWFELD, S. J., RAFTERY, L. A., CHARTOFF, E. H. and GELBART, W. M. (1995). Genetic characterization and cloning of mothers 
against dpp, a gene required for decapentaplegic function in Drosophila melanogaster. Genetics 139, 1347-58.

SHIBUYA, H., IWATA, H., MASUYAMA, N., GOTOH, Y., YAMAGUCHI, K., IRIE, K., MATSUMOTO, K., NISHIDA, E. and UENO, N. (1998). Role of TAK1 and TAB1 in BMP signaling in early Xenopus development. Embo J17, 1019-28.

SMITH, W. C., MCKENDRY, R., RIBISI, S., JR. and HARLAND, R. M. (1995). A nodal-related gene defines a physical and functional domain within the Spemann organizer. Cel/82, 37-46.

SPEMANN, H. and MANGOLD, H. (1924). Über die induktion von embryonalanlagen durch implantation artfremder organisatoren. Wihlem Roux's Arch. Entw. Mech. Org. 100, 599-638.

SPEMANN, H. and MANGOLD, H. (1924). Über die induktion von embryonalanlagen durch implantation artfremder organisatoren. Wihlem Roux's Arch. Entw. Mech. Org. 100, 599-638. See also recent translation Induction of embryonic primordia by implantation of organizers from a different species in Int. J. Dev. Biol. (2001) 45: 12 38.

SUZUKI, A., CHANG, C., YINGLING, J. M., WANG, X. F. and HEMMATI-BRIVANLOU, A. (1997a). Smad5 induces ventral fates in Xenopus embryo. Dev Bio/184, 402-5.

SUZUKI, A., KANEKO, E., UENO, N. and HEMMATI-BRIVANLOU, A. (1997b). Regulation of epidermal induction by BMP2 and BMP7 signaling. Dev Bio/189, 11222.

SUZUKI, A., SHIODA, N. and UENO, N. (1995). Bone morphogenetic protein acts as a ventral mesoderm modifier in early Xenopus embryos. Dev. Growth and Differ.

SUZUKI, A., UENO, N. and HEMMATI-BRIVANLOU, A. (1997c). Xenopus msx1 mediates epidermal induction and neural inhibition by BMP4. Development 124, 3037-44.

THOMSEN, G. H. (1996). Xenopus mothers against decapentaplegic is an embryonic ventralizing agent that acts downstream of the BMP-2/4 receptor. Development $122,2359-66$.
TOPPER, J. N., CAI, J., QIU, Y. ANDERSON, K. R., XU, Y. Y., DEEDS, J. D., FEELEY, R., GIMENO, C. J., WOOLF, E. A., TAYBER, O., MAYS, G. G., SAMPSON, B. A., SCHOEN, F.J., GIMBRONE, M. A., JR. and FALB, D. (1997). Vascular MADs: two novel MAD-related genes selectively inducible by flow in human vascular endothelium. Proc Natl Acad Sci U S A 94, 9314-9.

TRINDADE, M., TADA, M. and SMITH, J. C. (1999). DNA-binding specificity and embryological function of Xom (Xvent-2). Dev Bio/216, 442-56.

TSUNEIZUMI, K., NAKAYAMA, T., KAMOSHIDA, Y., KORNBERG, T. B., CHRISTIAN, J. L. and TABATA, T. (1997). Daughters against dpp modulates dpp organizing activity in Drosophila wing development. Nature 389, 627-31.

WADDINGTON, C. H. (1933). Induction of the primitive streak and its derivatives in the chick. J. Exp. Biol. 10, 38-46.

WEINSTEIN, D. C. and HEMMATI-BRIVANLOU, A. (1999). Neural induction. Annu Rev Cell Dev Biol 15, 411-33.

WILSON, P. A. and HEMMATI-BRIVANLOU, A. (1995). Induction of epidermis and inhibition of neural fate by Bmp-4. Nature 376, 331-3.

WILSON, P. A., LAGNA, G., SUZUKI, A. and HEMMATI-BRIVANLOU, A. (1997). Concentration-dependent patterning of the Xenopus ectoderm by BMP4 and its signal transducer Smad1. Development 124, 3177-84.

WITTA, S. E., AGARWAL, V. R. and SATO, S. M. (1995). XIPOU 2, a noggin-inducible gene, has direct neuralizing activity. Development 121, 721-30.

XU, R. H., KIM, J., TAIRA, M., ZHAN, S., SREDNI, D. and KUNG, H. F. (1995). A dominant negative bone morphogenetic protein 4 receptor causes neuralization in Xenopus ectoderm. Biochem Biophys Res Commun 212, 212-9.

ZIMMERMAN, L. B., DE JESUS-ESCOBAR, J. M. and HARLAND, R. M. (1996). The Spemann organizer signal noggin binds and inactivates bone morphogenetic protein 4. Cel/86, 599-606. 